\title{
DEVELOPMENT OF A NEW GEOSPATIAL DATA SHARING/OVERLAY SYSTEM FOR LAND ENVIRONMENTAL STUDIES - CERES GAIA -
}

\author{
R. Tateishi ${ }^{\text {a }}$, J.T. Sri Sumantyo ${ }^{a}$, A. Miyazaki ${ }^{\text {b }}$, H. Sumitani ${ }^{\text {b }}$ \\ a CEReS, Chiba Univeristy, 263-8522 Chiba, Japan - tateishi@faculty.chiba-u.jp \\ ${ }^{\mathrm{b}}$ Multisoup, Co.,Ltd. 151-0072 Tokyo, Japan
}

Commission IV, WG IV/4

KEY WORDS: Data sharing, Web-based, Database, Geospatial data, Open system, Land applications

\begin{abstract}
:
A new geospatial data sharing/overlay system, CEReS Gaia, has developed. The purpose of the system development is to promote land surface environmental studies. The system has developed to meet the requirements by academic users who wish easy data analysis by using his/her own data with existing other data. The system has the following features; a) internationally unlimited expansion of servers, b) multi-language capability (currently, only English), c) free access without user registration, d) data upload/download by registered users, e) capability to overlay user's data on other registered data, f) option of open or selective data distribution.
\end{abstract}

\section{INTRODUCTION}

Since environmental problems were widely recognized as a critical issue for human beings in 1980s, environmental studies were promoted rapidly. Then many earth observation satellites have been launched for environmental monitoring and many environmental datasets have been produced.

Global Change Master Directory (GCMD) [website 1] by NASA, which is currently the largest metadata inventories for global change and Earth science research, was initially developed in around 1990. The International Society for Photogrammettry and Remote Sensing (ISPRS) established working group on global environmental databases and investigated situations and problems of database productions in various fields such as land cover, elevation, hydrology, climate, soil, biodiversity, etc (Tateishi and Hastings, 2000 \& 2002). One of the recommendations of the working group was the development of integrated global environmental databases which is also mentioned by (Giri, et al. 2009). Recently, Group on Earth Observations (GEO) started GEO portal which collects various environmental data for nine societal benefits [website 2]. On the other hand, several universities of the U.S. developed portal sites not only for environmental data but for general geospatial data after around 2000. A representative one is Harvard Geospatial Library which offers user-friendly interface [website 3].

Most of the existing portal sites for data sharing/publication aims to disseminate final dataset products to all people. However, in the course of research and education of land environmental science, we often need to share the intermediate datasets in the process of the dataset production only within a limited group such as a laboratory, a working group, an institute, or a class. Also, for the environmental analysis, we often need to overlay his/her own data with existing data. Therefore userfriendly overlay function is necessary for the data analysis. To meet these requirements, the authors developed a new geospatial data sharing/overlay system, CEReS Gaia.

\section{CONCEPT OF GEOSPATIAL DATA SHARING / OVERLAY SYSTEM, CERES GAIA}

The basic concept of a new geospatial data sharing/overlay system, CEReS Gaia (Figure 1), is as follows.

a) cluster system

b) open source

c) international expansion of servers

d) multi-language capability

e) free access without user registration

f) data upload/download by registered users

g) types of acceptable geospatial data: satellite data, thematic data, digitized map data, ground measured data, ground photos, georegistered documents

h) search function by keywords or location

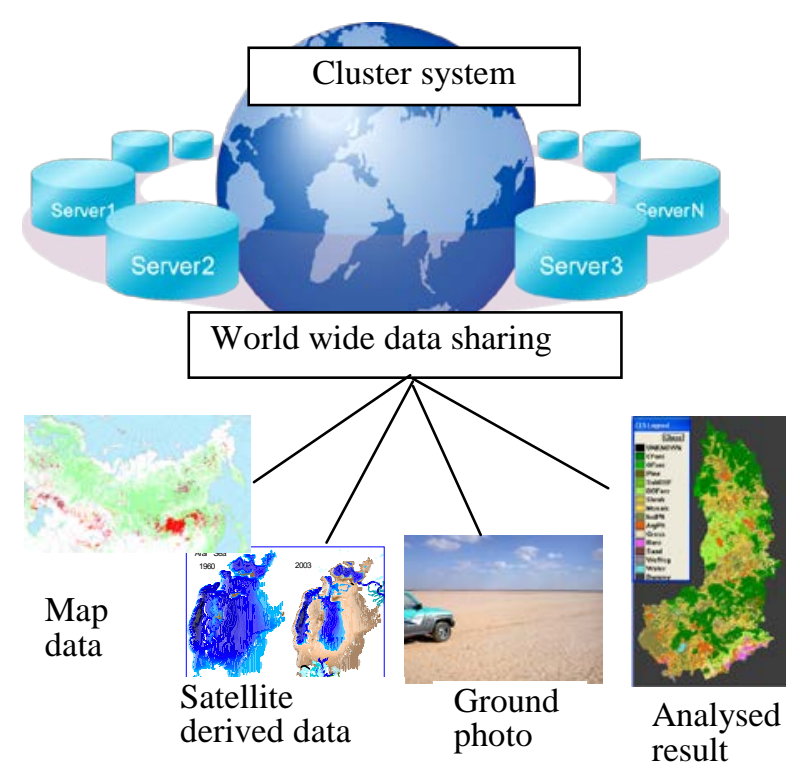

Figure 1 A new geospatial data sharing system, CEReS Gaia 
i) capability to overlay user's data on other registered data

j) options of data accessibility: single use, group use, open public distribution

\section{USER TYPES}

The developed system has five types of users as listed below. Super user, server managers, group leaders, and registered users are in the hierarchical structure, and the upper one has a right to approve the direct lower one. Registered users can download the data in the system and upload his/her own data to the system, while unregistered users (general public) can see the data in the system.

\section{(a) Super user}

- manages a total system and a main server

- has right to approve 'system manager'

(b) System managers

- manage a local server

- have right to approve 'group leader'

(c) Group leaders

- have right to approve 'general registered users'

(d) Registered users

- have right to upload/download data

(e) Unregistered users

- can see the data and overlay his/her own data on them

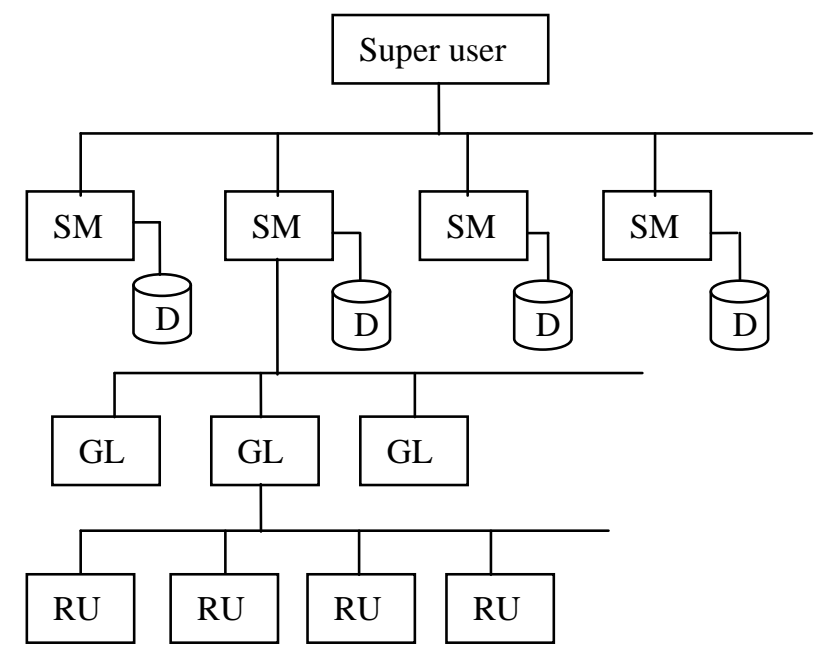

SM: System manager

GL: Group leader

RU: Registered user

D: Database

Figure 2 Structure of CEReS Gaia users

\section{USEFULNESS OF THE SYSTEM}

Registered users can use the developed system, CEReS Gaia, for the following ways.

- $\quad$ share his/her data only within a user group such as a working group

- distribute his/her data to the public

- $\quad$ analyse his/her data by overlaying with other data in the system

- $\quad$ publish his/her geo-registered research output

- $\quad$ accumulate geo-registered research outputs by an academic society
- $\quad$ check his/her land cover training/validation data with other data in the system

\section{DISCUSSION}

The first step of data sharing is to publish the produced data. For example, in the case of global land cover mapping, if all mapping projects shares their land cover training data, we will have enough number of training data for the next mapping attempt. Generally, the first action to share the data is to publish the data. Actually, many research organizations publish their produced data. Why do we need to collect these published data? The reason is the efficiency of data analysis. If we download each data we need from different distributors, it takes much time. The recommended way is to see and analyse multiple data in one portal site.

There have been developed many geospatial web-based databases for data sharing. Among them, some portal sites such as Harvard Geospatial Library are well developed with userfriendly interface. However no single portal site can cover all user's needs in different fields. In the future, it is recommended to link existing portal sites each other because each portal sites has specific advantage.

The developed portal site has unique advantages in efficient overlay function, data sharing in a limited group members, and the international server expansion.

\section{CONCLUTION}

A new geospatial data sharing/overlay system, CEReS Gaia, has developed as a tool of research and education of land environmental science. Among other existing geospatial data sharing portal sites, the developed system has features of data sharing capability within a specific user group and a capability to expand many servers worldwide. Any researcher who is interested in using CEReS Gaia actively as a "system manager" or "group leader" can contact the authors.

\section{References}

Giri, C., Hastings, D., Reed, B. and Tateishi, R., 2009. Status and Future of Global Databases. Chapter 9, Manual of Geographic Information Systems, ASPRS, pp.113-139,

Tateishi, R. and D. Hastings (Ed.), 2000. Global Environmental Databases, ISPRS WG IV/6 (1996-2000), Geocarto International, 250p.

Tateishi, R. and D. Hastings (Ed.), 2002. Global Environmental Databases vol.2, ISPRS WG IV/8 (2000-2004), Geocarto International, $154 \mathrm{p}$.

website 1: GCMD http://gcmd.nasa.gov/ (access 15 Apr. 2011)

website 2: GEO portal http://www.geoportal.org/ (access 15 Apr. 2011)

website 3: Harvard Geospatial Library, http://calvert.hul.harvard.edu:8080/opengeoportal/ (access 15 Apr. 2011)

\section{Acknowledgements}

This work was supported by Japan Society for the Promotion of Science (JSPS) research grant, KAKENHI(22220011). 